\title{
TESIS YERI SEÇIMINE YENI BIR BAKIŞ: KATMANLI ÇOK KRITERLI KARAR VERME YÖNTEMI
}

\author{
Emine Nur NACAR ${ }^{1}$, Babek ERDEBiLLi²
}

ÖZET

Amaç: Geleneksel Çok Kriterli Karar Verme (ÇKKV) yöntemleri yakın gelecekte karşış̧ılabilecek sorunlara çözüm verememektedir. Problemi baştan yeni ağılıklar atayarak çözmek yorucu ve zor olacağından, yakın gelecekte meydana gelebilecek intimaller için Katmanlı Çok Kriterli Karar Verme (KÇKKV) Yöntemi geliştirilmiştir.

Yöntem: Bu makalede, KÇÇKV yönteminin işleyişi anlatılmış ve geleneksel ÇKKV yöntemlerinden olan TOPSIS yöntemi ile karşılaştırılarak Ankara Sincan Organize Sanayi Bölgesinde faaliyet gösteren savunma sanayi firmasında örnek bir çalışma gerçekleştirilip iki yöntemin farkı tartışılmıştır.

Bulgular: Tesis yeri seçimi probleminde, KÇÇKV yöntemi ile en iyi alternatif seçilmiştir. Geleneksel ÇKKV yöntemlerinden TOPSIS ile KÇKKV kıyaslanmış ve yakın gelecekte gerçekleşebilecek olayların tesis yeri seçimini etkilediği görülmüştür.

Özgünlük: Literatürde KÇKKV yöntemi kullanılarak tesis yeri seçiminin yapıldığı bir çalışmaya rastlanmamıştır. Yapılan çalışmanın literatürdeki bu eksikliği dolduracağı ve farklı karar verme problemleri için de yol gösterici olacağı öngörülmektedir.

Anahtar kelimeler: Katmanlı Çok Kriterli Karar Verme Yöntemi, Tesis Yeri Seçimi, TOPSIS.

JEL Kodları: D39, D70, D81, R53.

\section{A NEW PERSPECTIVE ON FACILITY LOCATION SELECTION: STRATIFIED MULTI CRITERIA DECISION MAKING METHOD}

\begin{abstract}
Purpose: Traditional Multi-Criteria Decision Making (MCDM) methods cannot provide solutions to problems that may be encountered in the near future. Since it would be difficult to solve the problem by assigning new weights from the beginning, Stratified Multi-Criteria Decision Making (SMCDM) Method is used for the possibilities that may occur in the near future.

Methodology: In this article, the SMCDM method is explained and a sample study is carried out in a defense industry company operating in Ankara Sincan Organized Industrial Zone by comparing it with the TOPSIS method, which is one of the traditional MCDM methods, and the difference between the two methods is discussed.

Findings: In the facility location selection problem, the best alternative was selected with the SMCDM method. TOPSIS , one of the traditional MCDM method, and SMCDM methods were compared with each other, and it was seen that the events that may occur in the near future affect the facility location selection. Originality: There is no study in the literature in which facility location selection was made using the SMCDM method. It is predicted that the study will fill this gap in the literature and will be a guide for different decision-making problems.
\end{abstract}

Keywords: Stratified Multi-Criteria Decision-Making Method, Facility Location Selection, TOPSIS. JEL Codes: D39, D70, D81, R53.

\footnotetext{
1 Arş. Gör., Ankara Yıldırım Beyazıt Üniversitesi, Mühendislik ve Doğa Bilimleri Fakültesi, Endüstri Mühendisliği Bölümü, ennacar@ybu.edu.tr, ORCID: 0000-0003-3785-1928 (Sorumlu Yazar-Corresponding Author)

2 Doç. Dr., Ankara Yıldırım Beyazıt Üniversitesi, Mühendislik ve Doğa Bilimleri Fakültesi, Endüstri Mühendisliği Bölümü, berdebilli@ybu.edu.tr, ORCID: 0000-0001-8860-3903
} 


\section{GiRiş}

Geçtiğimiz yıllarda, kuruluşlar geliştiğinden iş süreçleri daha karmaşıkve entegre hale gelmiştir (Formaneck, 2019). Bu nedenle eski yöntemler işletmelerin sorunlarına cevap vermekte yetersiz kalmaktadır. Çok kriterli karar verme (ÇKKV) yöntemleri genel olarak karar değişkenleri ve ağırlıklarını da dikkate alarak alternatifler arasında sıralama yapıp en iyi alternatifi seçmeyi amaçlar. Bir ÇKKV problemini çözmek, alternatiflerin nitelikler üzerindeki etkisine yönelik objektif bir soruşturmaya ve karar vericinin tercih sisteminin öznel bir değerlendirmesine dayanır (Henig ve Buchanan, 1996). Bu nedenle karar verildikten sonra, karar verici kriterlere doğru ağırlıkların verildiğinden şüphe duyabilir. Çünkü bu kriterlerde yakın gelecekte değişmeler olabilir. Geleneksel ÇKKV yöntemlerinde yakın gelecekte olabilecek olaylar göz ardı edilmemelidir. ÇKKV yöntemlerinin yapısı yakın gelecekte olması beklenen olayları algoritmaya eklemeye müsait değildir. Bu sebeple yakın gelecekte olması beklenen olayları da dikkate alan katmanlı çok kriterli karar verme (KÇKKV) yöntemi geliştirilmiştir (Asadabadi, 2018). Geçtiğimiz birkaç on yılda, kuruluşlar gelişmiş ve iş süreçleri daha karmaşık ve entegre hale gelmiştir. Yöneticilerin çalışma şekli, kısmen, işin daha az emek yoğun ve teknolojiye daha bağımlı hale gelmesi nedeniyle önemli ölçüde değişiklik göstermiştir.

Literatüre yeni kazandırılan bu yöntemde, katmanlaşma kavramı ve ÇKKV yöntemi hibrit edilerek bütünleşmiş bir yaklaşım kullanılmıştır. Katmanlaşma kavramı planlama, robotik, optimal kontrol, takip, çoklu hedef optimizasyonu, keşif, arama ve diğer alanlarda önemli uygulamalar için bir potansiyele sahip olmakla birlikte anlaşılması ve uygulanması kolaydır (Zadeh, 2016). Katmanlaşma kavramı, istenen bir duruma ulaşmak için birkaç durumdan geçen bir sistemi tarif eder. Bu kavram, etkili ve kolay olan bir problem çözme yaklaşımıdır. Bu yaklaşımın önümüzdeki yıllarda farklı alanlara da uygulanacağı varsayılmaktadır (Asadabadi ve diğerleri, 2018).

Tesis yeri seçimi, bir firmanın operasyonları gerçekleştirebilmesi için birtakım kriterler de dikkate alınarak gerekli coğrafi alanın belirlenmesidir. Tesis yeri kararı, faaliyetlerini konumlandırmak, yerini değiştirmek veya genişletmek isteyen kurulușları içerir. Tesis yeri karar süreci, tanımlama, analiz, değerlendirme ve alternatifler arasından seçim yapmayı kapsar (Yang ve Lee, 1997). Bir fabrika yeri seçimi firmalar için maliyeti yüksek sonuçlar doğurabilmesi yönüyle oldukça önemli bir karardır (Üreten, 2006). Çünkü tesis yeri bir kere belirlendikten, kurulduktan ve taşınma işlemi de gerçekleştikten sonra geri döndürülmesi zordur (MacCarthy ve Atthirawong, 2003). Bu nedenle uzun vadeli stratejik bir öngörü gerektirir. Ayrıca belirlenecek olan tesis yeri konumunun işletme maliyetleri ve gelirleri üzerinde etkisi vardır. Kötü bir tesis yeri seçimi, aşırı nakliye maliyetlerine, kalifiye iş gücü sıkıntısına, rekabet avantajının kaybolmasına, yetersiz ham madde tedariğine veya operasyonlara zarar verebilecek benzer koşullara neden olabilir.

Bir tesis yeri seçimi için yatırım yapacak olan işletme sahibi, verimlilik, etkinlik ve karlılık gibi kavramları göz önünde bulundurarak işletme için en uygun tesis yerinin belirlenmesini amaçlar (Korkut ve diğerleri, 2010). Bu tesis yeri seçimi hususunun etkin olarak dikkate alınabileceği en uygun alan da problemin birden çok kriteri göz önünde bulundurması yönüyle ÇKKV yöntemleridir. Tesis yeri seçimi problemleri etkin ve verimli bir tedarik zinciri için oldukça önemli bir karardır. Tedarik zinciri; üretici, tedarikçi, perakendeci ve tüketici gibi ilgili işletmenin de içinde bulunduğu birçok halkayı içerir. Hatta bir işletme, birden çok tedarik zincirinin mensubu durumunda olabilir. Tesis yeri seçimi yapacak olan işletmenin etkin bir karar alamaması sadece kendisini değil, bu tedarik zincirlerinin tüm elemanlarını etkiler. Bu etki, ham madde tedariği problemi, sipariş gecikmeleri, defolu sipariş teslimleri, aşırı fire artışı, lojistik maliyetleri gibi birçok şekilde olabilir. Bu sebeple sadece işletmenin verimi düşmekle kalmaz, tedarik zincirindeki tüm elemanların bundan etkilenmesi sebebiyle sektörün genel veriminin düşmesine kadar gidebilecek ulusal bir problem haline dahi gelebilir. Bu nedenle, işletmenin hem bireysel hem de ulusal menfaati düşünerek hareket etmesi gerekir.

$\mathrm{Bu}$ çalışmanın temel amacı, literatüre yeni kazandırılan bir yöntem olan KÇKKV yöntemini karar verme problemlerine adapte ederek akademik çalışmaların yanı sıra endüstride de kullanılabileceğini göstermektir. 2018 yılında Asadabadi tarafından yayınlanan yöntem baz alınarak alanda ulusal bir çalışma 
olmaması gerekçesiyle ülkemizde rastlanan tesis yeri seçimi problemine adapte edilmiştir. Temel olarak ÇKKV yöntemleri karar verme problemleri için oldukça zengin algoritma literatürüne sahiptir. Ancak KÇKKV yöntemi, şu zamana kadar değinilmemiş bir sorun olan süreçteki değişimlerden yola çıkılarak geliştirilmiş olan bir yöntemdir. Hayatta gelişmeler ve değişmeler olağan durumlardır. Her şeyin planlı gitmesi gibi bir durum söz konusu değildir. Geleneksel ÇKKV yöntemleri bu değişimleri hesaba katmaz. Yeni bir gelişmede sürece en baştan başlamak ve problemi başından çözmek gerekir. Bu da büyük para ve zaman kayıplarına yol açar. Aslında KÇKKV yönteminin geliştirilme amacı karar verme problemlerini daha verimli hale getirmek ve süreç içerisinde yaşanan kayıpları önlemektir. Uygulamada da gözleneceği üzere geleneksel yöntemlere nazaran oldukça başarılı sonuçlar elde edilmiştir.

Çalışmanın giriş bölümünde Katmanlı Çok Kriterli Karar Verme (KÇKKV) yönteminin gerekliliği ve geleneksel Çok Kriterli Karar Verme (ÇKKV) yöntemlerinden farklılığı anlatılmıştır. İkinci bölümde, literatür araştırması yapılarak ÇKKV yöntemleri ve TOPSIS yöntemi ile yapılan tesis yeri seçimi çalışmaları ve katmanlaşma kavramından bahsedilmiştir. Üçüncü bölümde, TOPSIS ve KÇKKV yöntemlerinin algoritmik yapısı tanıtılmıştır. Dördüncü bölümde, TOPSIS yöntemi ve KÇKKV yöntemleri anlatılarak gerçek bir vaka analizi ile sonuçları karşılaştırılmıştır. Sonuç bölümünde ise yöntemlerin avantaj ve dezavantajları ile geleceğe yönelik çalışmalardan bahsedilmiştir.

\section{LITERATÜR ARAŞTIRMASI}

Tesis yer seçimi problemleri; faaliyet yerini seçmek, değiştirmek ya da genişletmek kararlarında kullanılır. Bu amaçla alternatifler arasında tanımlama, analiz, değerlendirme ve seçim süreçleri gerçekleştirilir (Yang ve Lee, 1997). Tesis yer seçimi problemleri, doğabilecek riskleri gözden geçirme, şirketin intiyaçlarını ve iş gücü kapasitesini analiz etme yönleriyle stratejik bir karar verme sürecinden geçer. Bu sebeple kaynak kullanımını en yükseğe çıkarıp maliyeti en aza indirgeyerek problemi optimize etmek gerekir. Bu bölümde öncelikle tesis yer seçimi problemlerinde ÇKKV yöntemlerinden TOPSIS yöntemi çalışmaları değerlendirilmiştir. Daha sonra katmanlaşma kavramı çalışmaları incelenerek çalışmanın özgün niteliğinden bahsedilmiştir.

\subsection{TOPSIS Yöntemi ile Tesis Yer Seçimi}

Tesis yer seçimi problemleri, firmalar açısından önemli bir husus olduğundan şu zamana kadar birçok araştırmaya konu olmuştur. Şekil 1'de tesis yeri seçimi için yapılan akademik çalışmaların yıllara göre dağılımı gösterilmiştir. 1997'de yapılan bir çalışmada ÇKKV yöntemlerinden biri olan Analitik Hiyerarşi Süreci (AHP) kullanılarak 4 ana kriter (pazar, ulaşım, iş gücü, topluluk) ve bunlara bağlı olan 12 alt kriter belirlenmiş ve 3 alternatif bölge arasından en iyisi seçilmiştir (Yang ve Lee, 1997). 2003 yılında ÇKKV yöntemleri ile bulanık mantık hibrit edilerek hem sayılabilen hem sayılamayan kriterleri içeren 4 farklı bulanık ÇKKV yaklaşımı üzerinde çalışılmış ve en iyi tesis yer seçiminin daha objektif olarak yapılabilmesi sağlanmıştır (Kahraman ve diğerleri, 2003). 2006 yılında kalite fonksiyon dağıtımı (QFD), analitik hiyerarşi süreci (AHP) ve analitik ağ süreci (ANP) kullanılarak iç ve dış faktörlerin birlikte ele alındığı stratejik bir tesis yer seçimi problemi üzerinde çalışılmıştır (Partovi, 2006). Değerlendirme prosedürlerinin çeşitli hedefleri ve çözümleri içerdiği; problemin farklı bir yaklaşımı olan, istenmeyen tesis yeri seçiminde ÇKKV yöntemlerinden biri olan analitik ağ süreci (ANP) yöntemi kullanılmış ve kriterler arasında bir uzlaşma sağlanmaya çalışılmıştır (Tuzkaya ve diğerleri, 2008). 2008 yılında bir tesis yer seçimi problemi için bulanık TOPSIS ve bulanık AHP yöntemleri karşılaştırılarak benzerlikleri ve farklılıkları analiz edilmiştir (Ertuğrul ve Karakaşoğlu, 2008). 2011 yılında yapılan bir çalışmada sosyal ve ekonomik faktörler de göz önünde bulundurularak Analitik Hiyerarşi Süreci (AHP) ile otopark yer seçimi yapılmıştır (Deluka-Tibljas ve diğerleri, 2011). Benzinlik yeri seçimi için yapılan bir çalışmada ÇKKV yöntemleri kullanılarak sol ve sağ skorlara dayalı yeni bulanık ağırlıklı ortalama (FWA) yöntemi uygulanmış ve gerçek hayattan bir örnekle yöntemin daha doğru, esnek ve kullanımı kolay olduğu görülmüştür (Mokhtarian, 2011). Chen (2000) tarafından yapılan çalışmada TOPSIS yöntemi bulanık mantıkla hibrit edilerek değerlendirilmiş; her bir alternatifin derecesi ve her bir ölçütün ağırığı, üçgen bulanık sayılarla ifade edilebilecek dilsel terimlerle açıklanmıştır. Daha sonra, iki üçgen bulanık sayı arasındaki mesafeyi hesaplamak için bir tepe yöntemi önerilmiştir. Böylelikle gerçeğe daha yakın bir sonuç elde edilmeye çalışımıştır. Bu çalışma genişletilerek tesis yeri seçimi problemine adapte edilmiş, 
dilsel ortamlarda yer seçimine yönelik yeni bir TOPSIS yaklaşımı sunulmuş, çeşitli alternatif konumların çeşitli kriterler altında derecelendirilmeleri ve çeşitli kriterlerin ağılıklarının dilbilimsel terimlerle bulanık sayılarla değerlendirilmesi yapılmıştır (Ertuğrul, 2011; Yong, 2006). 2012 yılında, İran'daki büyük bir şirketin gerçek bir depo yeri seçimi sorununda bulanık TOPSIS yöntemi uygulanmıştır. Yöntem 2 aşamada gerçekleştirilmiştir. 1. adımda, depo yeri seçimi için kriterler belirlenmiş, 2. adımda, uzmanlar seçilen kriterlere karşı potansiyel alternatiflere dilsel derecelendirme yapmışlardır (Ashrafzadeh ve diğerleri, 2012). Mokhtarian ve Hadi-Vencheh (2012) bulanık MCDM problemlerini çözmek için sol ve sağ skorlara dayanan yeni bulanık TOPSIS yöntemi geliştirmişlerdir. Üç sayısal örnek verilerek önerilen yöntemi uygulanmıştır. Illk iki sayısal örnek karşılaştırma amacıyla önerilmiştir. Üçüncü örnekte, süt ürünleri fabrikası inşa etmek için çeşitli sanayi bölgeleri arasında bir seçimin yapıldığı gerçek bir uygulamadır. Özdağoğlu, (2012) tarafından yapılan çalışmada ölçüt kümesinin hiyerarşi yapısı üzerinde birbirleriyle etkileşimleri içerdiği çok kriterli bir tesis yeri seçimi problemi için bulanık bir ANP yöntemi geliştirilmiştir. Tesis lokasyonunda bulanık ANP modeli geliştirme ve uygulamasının yanı sıra, alternatif lokasyonların önem düzeyleri için alt ve üst sınırları belirten duyarlılık analizi de yapılmıştır. Mokhtarian ve diğerleri (2014) karar verme sürecinde belirsizlik riskinin azaltılmasına dayanan IVF-VIKOR yöntemini kullanmışlardır. Böyle bir yöntem kullanılarak, bir IVF karar verme probleminde yakalanan kararların güvenilirliği önemli ölçüde artmaktadır. Önerilen yöntem, birincisi, İran'ın en büyük şehirlerinden birinde belediye ıslak atık depolama sahasında bazı çukurları kazmak için uygun bir yer seçmekle ilgili gerçek bir uygulama sorunu olan iki sayısal örneğin çözümü için uygulanmıştır. İkinci sayısal örnek, yöntemi diğer iki IVF-MCDM yöntemiyle karşılaştırmak amacıyla sunulmuştur. Erdoğan ve Kaya (2016), nükleer santral yeri seçiminde alternatiflerin ağırlıklandırılması için aralık tip-2 bulanık TOPSIS'in ve kriterlerin ağırlıklandırılması aralık tip-2 bulanık analitik hiyerarşi sürecinden (AHP) oluşan birleşik bulanık ÇKKV yöntemini kullanarak en iyi alternatifi seçmişlerdir. Tedarik zinciri risk yönetimi konusunda Çalık (2018) tarafından yapılan bir çalışmada dört otomotiv tedarikçisi; finansal risk, bilgi riski, sosyal ve çevresel risk, operasyonel risk, tedarik riski, talep riski ve ürün kurtarma riski kriterleri kullanılarak kıyaslanmıştır. Çalışmada dört aşamadan oluşan bütünleşik AHP ve TOPSIS yaklaşımları kullanılmıştır. Belirlenen altı risk kategorisi için öncelikli sıralama elde edilmiştir. Deveci ve diğerleri (2018) ekmek fabrikası tesisinin yerini belirlemek için iki aşamalı bir metodoloji önermişlerdir. Bunlar hem Coğrafi Bilgi Sistemleri (CBS) hem de ÇKKV tekniklerine dayanmaktadır. Metodolojinin ilk aşaması, CBS uygulayarak seçim etkinliğini basitleştirmek için olası alternatif yerlerin sayısını azaltmayı amaçlamaktadır; ikinci aşamada, ekmek fabrikası sahasının yerini tam olarak belirlemek için aralık tip-2 bulanık ÇKKV yaklaşımını kullanılmıştır. Koçak ve Çalık (2020) tarafından yapılan bir çalışmada AHP ve TOPSIS yöntemleri kullanılarak beş alternatif bankadan en iyisinin seçilmesi amaçlanmıştır. Bunun için mevduat faiz oranı, kredi faiz oranı, ATM sayısı, ücret ve komisyonlar, tavsiye ve personel özellikleri olmak üzere altı kriter belirlenmiştir. Aralık tip-2 bulanık sayılarla analiz yapılan çalışmada faiz oranlarına ait kriter değerlendirmelerinde karar vericilere göre performansı genel olarak iyi olduğundan en iyi alternatif olarak dördüncü banka seçilmiştir. Seker ve Aydin (2020), Türkiye'nin kuzeyindeki bir hidrojen enerjisi hidrojen-sülfür (H2S) ayrıştırma tesisi kurmak için en uygun yeri seçmeyi amaçlamıştır. Araştırmalara göre Karadeniz, H2S'yi almak için en zengin sulardan biri olarak belirlenmiştir. Hidrojen enerji üretim tesisi için tesis yerinin seçilmesi stratejik kararlar gerektirdiğinden, bu çalışmada güçlü ve verimli bir araç olarak Çok Kriterli Karar Verme (ÇKKV) tercih edilmektedir. Buna göre, Entropi ve TOPSIS yöntemleri IVPF çerçevesinde uygulanmıştır. 


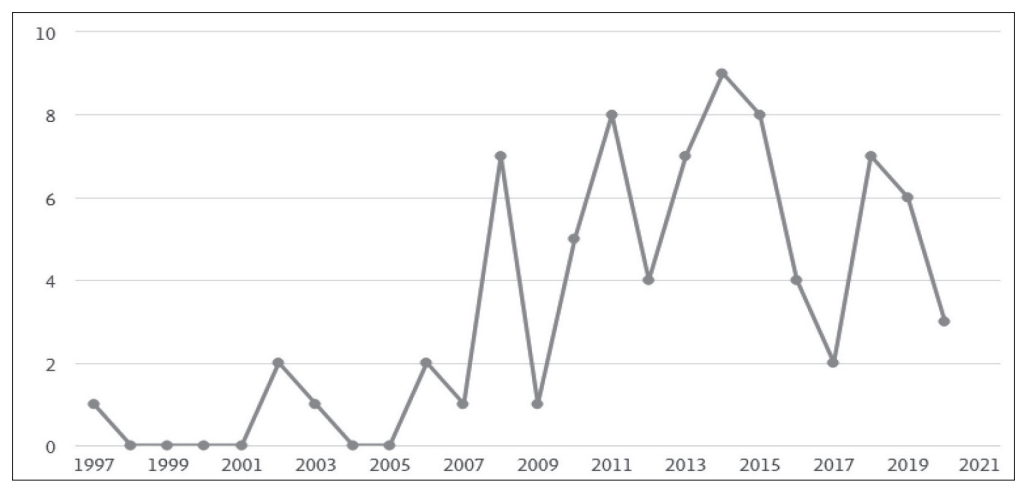

Şekil 1. Tesis yeri seçimi için yapılan akademik çalışmaların yıllara göre dağııımı (Scopus)

\subsection{Katmanlaşma Kavramı}

Katmanlaşma kavramı (CST) ilk olarak hesaplama nesnelerinin iç içe veya yığılmış tabakalar halinde düzenlendiği karmaşık büyük ölçekli sistemlerin analizinde ve tasarımında kullanılabilen bir kavram olarak literatüre kazandırımıştır (Zadeh, 2016). Bu kavram, bir dizi durumu dikkate alır ve sistemin bir durumdan diğerine geçişine dayanan girdileri (çıkışlarla ilişkili) alan bir sistemi tanımlar (Asadabadi ve Zwikael, 2019). Daha sonra, temel boyutları büyük veri olan lojistik bilişimin, katmanlaşma kavramı kullanılarak etkin bir şekilde modellenebildiği gösterilmiştir (Asadabadi ve diğerleri, 2017). Katmanlaşma kavramı, bulanık katmanlaşma ve üç boyutlu katmanlaşma olarak incelenmiş; gelecekteki kullanım alanları robotik, yapay zeka, doğal dil işleme ve büyük veri kavramlarıyla anlatılmıştır (Asadabadi ve diğerleri, 2018).

Asadabadi ve diğerleri (2018) tarafından yapılan çalışmada katmanlaşma konseptinin avantajları ve ana eksikliği gözden geçirilmiş, uygulanabileceği alanlar tartışılmıştır. Zadeh (2016), tarafından sunulan orijinal CST’nin genelliği göz önüne alındığında, gelecekteki çalışmalarda uygulanacak CST için farklı versiyonları olabileceği; bulanık CST, 3DCST ve çoklu CST içeren versiyonları sunulmuştur.

KÇÇKV yöntemi, kriter ağırlıklarındaki olası dalgalanmaları ele alarak ÇKKV yöntemlerinin uygulanmasını iyileştirmek amacıyla geliştirilmiştir. Son zamanlarda önerilen katmanlaşma kavramı, karar ortamını tabakalaştırmak için ÇKKV yöntemleri ile birlikte kullanılmıştır. Yöntem daha sonra tedarikçi seçim problemine uygulanmış ve geleneksel ÇKKV yöntemlerinden daha verimli olduğu sonucuna ulaşılmıştır (Asadabadi, 2018).

Asadabadi ve Zwikael (2019) tarafından yapılan çalışmada katmanlaşma kavramı bir inşaat projesinde uygulanmıştır. Projelerin ilk aşamalarında ortaya çıkan yüksek risk ve belirsizlik nedeniyle, bu tahminlerin proje planlama sırasındaki güvenilirliği zayıf kaldığından proje sırasında meydana gelebilecek olaylarla ilgili belirsizliği göz önünde bulundurabilen katmanlaşma kavramı, projede yer alan zaman ve maliyet tahminlerini hesaplamak için nasıl kullanılabileceği açıklanmıştır. Böylelikle, önerilen yöntem ile projelerin tamamlanma süresi ve maliyet tahminlerinin güvenilirliğini artırdığı savunulmuştur.

Literatürde katmanlı çok kriterli karar verme yöntemi kullanılarak tesis yeri seçiminin yapıldığı bir çalışmaya rastlanmamıştır. Yapılan çalışmanın literatürdeki bu eksikliği dolduracağı ve farklı karar verme problemleri için de yol gösterici olacağı öngörülmektedir. 
Çizelge 1: Tesis yeri seçiminde ÇKKV yöntemleri literatür analizi

\begin{tabular}{|l|l|}
\hline Makale Yazarları & Kullanılan ÇKKV Yöntemi \\
\hline Yang ve Lee (1997) & AHP \\
\hline Kahraman ve diğerleri (2003) & Bulanık ÇKKV \\
\hline Yong (2006) & TOPSIS \\
\hline Partovi (2006) & QFD, AHP, ANP \\
\hline Tuzkaya ve diğerleri (2008) & ANP \\
\hline Ertuğrul ve Karakaşoğlu (2008) & Bulanık TOPSIS, Bulanık AHP \\
\hline Deluka-Tibljas ve diğerleri (2011) & AHP \\
\hline Ertuğrul (2011) & TOPSIS \\
\hline Mokhtarian (2011) & FWA \\
\hline Ashrafzadeh ve diğerleri (2012) & TOPSIS \\
\hline Özdağoğlu (2012) & Bulanık ANP \\
\hline Mokhtarian ve Hadi-Vencheh (2012) & Bulanık TOPSIS \\
\hline Mokhtarian ve diğerleri (2014) & IVF-VIKOR \\
\hline Erdoğan ve Kaya (2016) & Bulanık TOPSIS, Bulanık AHP \\
\hline Deveci ve diğerleri (2018) & Bulanık ÇKKV \\
\hline Seker ve Aydin (2020) & Entropi, TOPSIS \\
\hline
\end{tabular}

\section{YÖNTEM}

\subsection{TOPSIS Yöntemi}

TOPSIS (Technique for Order Preference by Similarity to Ideal Solution), ÇKKV tekniği olarak geliştirilmiştir (Hwang ve Yoon, 1981). Yöntemin temeli pozitif ideal çözüme en kısa mesafe ve negatif ideal çözüme en uzak mesafedeki alternatifi seçmektir. Yöntemin adımları aşağıdaki gibidir (Dumanoğlu ve Ergül, 2010; Rouyendegh ve Saputro, 2014):

1. Adım: Karar matrisi (A) oluşturulur (Eşitlik 1). A karar matrisinin satırları alternatifleri, sütunları karar değişkenlerini temsil etmektedir.

$$
A_{i j}=\left[\begin{array}{ccccc}
a_{11} & a_{12} & a_{13} & \cdots & a_{1 p} \\
a_{21} & a_{22} & a_{23} & \cdots & a_{2 p} \\
a_{31} & a_{32} & a_{33} & \cdots & a_{3 p} \\
\vdots & \vdots & \vdots & \ddots & \vdots \\
a_{m 1} & a_{m 2} & a_{m 3} & \cdots & a_{m p}
\end{array}\right]
$$

2. Adım: A karar matrisi normalize edilir. Normalizasyon işlemi Eşitlik 2'de gösterilmiştir. Bu eşitlik kullanılarak Eşitlik 3'teki normalize karar matrisi elde edilmiştir.

$$
n_{i j}=\frac{a_{i j}}{\sqrt{\sum_{i=1}^{m} a_{i j}^{2}}}
$$

Böylelikle normalize edilmiş matris elde edilir. 


$$
N=\left[\begin{array}{ccccc}
n_{11} & n_{12} & n_{13} & \cdots & n_{1 p} \\
n_{21} & n_{22} & n_{23} & \cdots & n_{2 p} \\
n_{31} & n_{32} & n_{33} & \cdots & n_{3 p} \\
\vdots & \vdots & \vdots & \cdots & \vdots \\
n_{m 1} & n_{m 2} & n_{m 3} & \cdots & n_{m p}
\end{array}\right]
$$

3. Adım: Elde edilen normalize matrise ait her değer $w_{i}$ değeriyle çarpılarak Eşitlik 4 'te ifade edilen ağırlıklandırılmış normalize matris elde edilir.

$$
V=\left[\begin{array}{ccccc}
w_{1} n_{11} & w_{2} n_{12} & w_{3} n_{13} & \cdots & w_{n} n_{1 p} \\
w_{1} n_{21} & w_{2} n_{22} & w_{3} n_{23} & \cdots & w_{n} n_{2 p} \\
w_{1} n_{31} & w_{2} n_{32} & w_{3} n_{33} & \cdots & w_{n} n_{3 p} \\
\vdots & \vdots & \vdots & \cdots & \vdots \\
w_{1} n_{m 1} & w_{2} n_{m 2} & w_{3} n_{m 3} & \cdots & w_{n} n_{m p}
\end{array}\right]=\left[\begin{array}{ccccc}
v_{11} & v_{12} & v_{13} & \cdots & v_{1 p} \\
v_{21} & v_{22} & v_{23} & \cdots & v_{2 p} \\
v_{31} & v_{32} & v_{33} & \cdots & v_{3 p} \\
\vdots & \vdots & \vdots & \cdots & \vdots \\
v_{m 1} & v_{m 2} & v_{m 3} & \cdots & v_{m p}
\end{array}\right]
$$

4. Adım: Ağırlıklandırıımış normalize matris bazında, problem yapısına bağlı olarak maksimizasyon ya da minimizasyon durumuna göre ideal ve negatif ideal çözüm değerleri elde edilir.

5. Adım: İdeal ve negatif ideal noktalara olan uzaklık değerleri Eşitlik 5 ve 6'daki gibi elde edilir.

$$
\begin{aligned}
& S_{i}^{*}=\sqrt{\sum_{j=1}^{n}\left(v_{i j}-v_{j}^{*}\right)^{2}} \\
& S_{i}^{-}=\sqrt{\sum_{j=1}^{n}\left(v_{i j}-v_{j}^{-}\right)^{2}}
\end{aligned}
$$

6. Adım: İdeal çözüme göreli yakınlık Eşitlik 7'deki gibi hesaplanır.

$$
C_{i}^{*}=\frac{S_{i}^{-}}{S_{i}^{-}+S_{i}^{*}}
$$

$C_{i}^{*}, 1 \geq C_{i}^{*} \geq 0$ aralığında bir değer almalıdır.

\subsection{Katmanlı Çok Kriterli Karar Verme Yöntemi (KÇKKV)}

Asadabadi tarafından geliştirilen bu yaklaşımda geleneksel ÇKKV yöntemi, katmanlaşma kavramıyla hibrit edilerek bütünleşmiş bir yaklaşımla kullanılarak yeni bir metot oluşturulmuştur (Asadabadi, 2018). Şekil 2'de KÇKKV yönteminin akış diyagramı verilmiştir. Bu yönteme göre Zadeh (2016) tarafından belirlenen kavramlar aşağıdaki gibidir:

Sistem: Sistem bir nesneler topluluğudur. Evreler boyunca hedef kümeye geçiş yapar.

Evre: Evre, sistem değişkenlerinin değerleri ile ilişkilidir. Değişkenlerin değerleri değiştikçe sistem bir evreden diğerine geçer.

Evre Geçiş Fonksiyonu: Evre geçiş fonksiyonu Eşitlik 8'de ifade edildiği gibi $S_{t}$ 'inci evrede $u_{t}^{\prime}$ 'nin girdi olduğu i'inci evreden (i+1)'inci evreye geçişi temsil eder. 


$$
S_{(t+1)}=f\left(S_{t}, u_{t}\right)
$$

Hedef evre: Eğer $w_{i}$ sistemin ulaşılmak istenen amacıysa, $w_{i}$ hedef evredir.

Ulaşılabilirlik: Eğer $w_{i}$ 'dan $w_{j}^{\prime}$ ye bir geçiş yolu varsa; $w_{j}$, $w_{i}^{\prime}$ dan ulaşılabilir olarak tanımlanır.

Girdi $\left(u_{t}\right)$ ve Çıktı $\left(v_{t}\right)$ : Her evrede sistem bir girdi alabilir. Girdi bir çıktıyla ilişkilendirilir ve sistemin geçiş yaptığı sonraki evreyi belirler.

Yöntemin işleyişi aşağıdaki gibidir:

Alternatifler kümesi $\left\{a_{1}, a_{2}, \ldots, a_{n}\right\}$ ve kriterler kümesi $\left\{c_{1}, c_{2}, \ldots, c_{m}\right\}$ oluşturulur. Bu alternatifler ve kriterlere göre oluşturulan matris A, Eşitlik 9'daki gibidir.

$$
A=\left[\begin{array}{cccc}
q_{11} & q_{12} & \ldots & q_{1 m} \\
q_{21} & q_{22} & \ldots & q_{2 m} \\
\ldots & \ldots & \ldots & \ldots \\
q_{n 1} & q_{n 2} & \ldots & q_{n m}
\end{array}\right]
$$

Kriterlerin ağırlıkları, şu anki durumun devam edip etmemesine göre değişebileceğinden, kriter ağırlıkları kümesi Eşitlik 10'da gösterilmiştir.

$$
\text { Wt: }\left\{w t_{1}, w t_{2}, \ldots, w t_{m}\right\}
$$

Sistemdeki kararın $w_{i}^{\prime}$ nci evrede olduğu düşünülürse, sistemde h adet farklı evre birbirinin devamı niteliğinde olup kümesi Eşitlik 11'deki gibi ifade edilmektedir.

$$
\mathrm{W}:\left\{w_{1}, w_{2}, \ldots, w_{h}\right\}
$$

Her evre için ağırlıklar değişebilmektedir. Yöntemin uygulanabilmesi için karar verici tarafından hangi evrelerin gerçekleşme olasılıklarının diğerlerine göre daha fazla olduğu, evrelerin gerçekleşme olasılığının hesaplanabilir ya da tahmin edilebilir olması, her evredeki kriter ağırlıklarının tahmin edilebilir olması durumlarının sağlanması gerekmektedir. k'ıncı evredeki kriter ağırıkları kümesi Eşitlik 12'deki gibidir.

$$
\mathrm{W} t_{\mathrm{k}}:\left\{w t_{k 1}, w t_{k 2}, \ldots, w t_{k m}\right\}
$$

Evrelerin olasılıklarının yansıtıldığı Eşitlik 13’te P geçiş matrisi verilmiştir.

$$
P=\left[\begin{array}{cccc}
p_{11} & p_{12} & \ldots & p_{1 h} \\
p_{21} & p_{22} & \ldots & p_{2 h} \\
\ldots & \ldots & \ldots & \ldots \\
p_{h 1} & p_{h 2} & \ldots & q_{h h}
\end{array}\right]
$$

Sistemin k. evrede olduğu varsayılarak oluşturulan, bütün süreci ifade eden denklem Eşitlik 14'te ifade edilmiştir.

$$
V_{a i}=\sum_{t=1}^{m} q_{i t} \sum_{j=1}^{h} w t_{j t} p_{k j}
$$




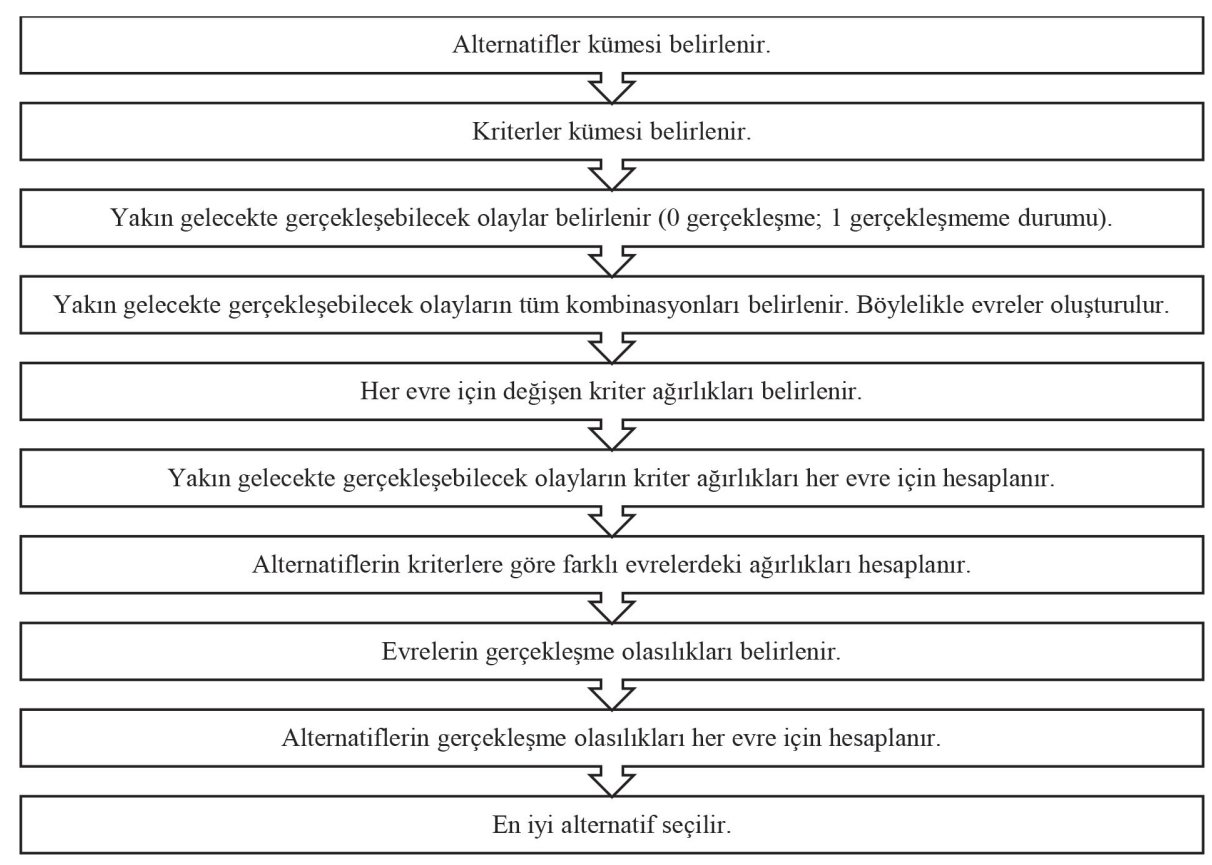

Şekil 2. KÇKKV yöntemi için akış diyagramı

\section{UYGULAMA}

Örnek çalışma, merkezi Ankara Sincan Organize Sanayi Bölgesinde olan bir fabrikada gerçekleştirilmiştir. Bahsedilen fabrika, kurumsal bir kimliğe sahip olup yıllardır savunma sanayi sektöründe tedarikçi olarak hizmet veren bir firmadır.

Fabrika müdürlerinin uzun zamandır üzerinde çalıştıkları yeni bir tesis kurma konusu, katmanlı ÇKKV yöntemi ile incelenmiştir. İlgili fabrika tarafından, yakın gelecekte gerçekleşebilecek olayların da dikkate alınması istenmiştir. Bu durum için, ÇKKV yöntemlerinin katı bir yapıda olup değişen koşullara izin vermemesinden ve her yeni olay için kriterlerin sürekli tekrar hesaplanıp sistemin ancak öyle çözülerek vakit kaybına sebep olmasından dolayı, problem çözümü için katmanlı ÇKKV yöntemi tercih edilmiştir.

Fabrika müdürleriyle yapılan görüşmeler sonucu, üç alternatif tesis yerinin göz önünde bulundurulduğu anlaşıımıştır. Bu alternatifler, gizlilik ilkesi çerçevesinde müdürlerin istekleri doğrultusunda Tesis 1, Tesis 2 ve Tesis 3 olarak isimlendirilmiştir. İlgili alternatifler analiz edilerek en çok önem arz eden 3 kriter belirlenmiştir. Bu kriterler; maliyet, kaynaklara erişilebilirlik ve çevresel riskler şeklindedir. Bu kriterlerin tesis yeri seçimi açısından önemi ve özelliği aşağıda belirtildiği gibidir:

Maliyet: Tesis yer seçiminde iki ana maliyet türü vardır: Sabit maliyet ve değişken maliyet. Sabit maliyet, yatırımın yanı sıra kurulum ve başlangıç maliyetini de içerir. Değişken maliyet; nakliye, operasyon, üretim, hizmetler, dağıtım, lojistik, atık bertarafı, bakım ve çevresel maliyet olabilir (Farahani ve diğerleri, 2010). Tesis yer seçimi yapılırken bu maliyetlerin tümü göz önünde bulundurulmalıdır.

Kaynaklara Erişilebilirlik: Ham madde, su, tedarikçilere yakınlık gibi özelliklerin uzun vadede daha büyük sorunlara yol açmasını önlemek adına erişilebilirliğin ve kullanımının verimli olması gerektiğinden kaynaklara erişilebilirlik bir diğer önemli tesis yer seçimi kriteridir.

Çevresel Riskler: Bu kriter içerisinde ulaşım riski, doğal risk, atık bertaraf/arıtma riski veya en yüksek yer olan genel "istenmeyen etkiler" yer almaktadır. Tesis yer seçimi problemlerinde çevresel risk oranı, maliyetten çok daha azdır (Farahani ve diğerleri, 2010). 
Kriterlerin ağırlıkları, fabrika müdürleriyle yapılan görüşmeler sonucu elde edilmiş ve Tablo 2'de gösterilmiştir.

Çizelge 2: Kriterlerin ağırlıkları

\begin{tabular}{|l|c|}
\hline Kriter & Ağırlık \\
\hline Maliyet & 0,4 \\
\hline Kaynaklara Erişilebilirlik & 0,3 \\
\hline Çevresel Riskler & 0,3 \\
\hline
\end{tabular}

Yukarıdaki kriterler göz önünde bulundurularak en optimal tesis yeri seçimi, karşılaştırma yapabilmek adına öncelikle genel ÇKKV yöntemiyle incelenmiş ve sıralama elde edilmiştir. Ardından sistem KÇKKV yöntemiyle çözülmüştür. Elde edilen sıralama, genel ÇKKV yöntemiyle karşılaştırılmıştır.

Tesis 1, Tesis 2 ve Tesis 3 verilen kriterler olan fiyat, kaynaklara erişilebilirlik ve çevresel risklere göre karşılaştırılmış ve Tablo 3’teki veriler elde edilmiştir.

Çizelge 3: Tesis yerlerinin kriterlere göre karşılaştırılması

\begin{tabular}{|c|c|c|c|}
\hline & Maliyet & Kaynaklara Erişilebilirlik & Çevresel Riskler \\
\hline Tesis 1 & 0,18 & 0,12 & 0,32 \\
\hline Tesis 2 & 0,15 & 0,24 & 0,26 \\
\hline Tesis 3 & 0,16 & 0,14 & 0,34 \\
\hline
\end{tabular}

Genel ÇKKV yöntemi bazında değerlendirilerek, Tablo 2'de verilen her tesis yeri için elde edilen kriter ağılıkları Tablo 1'deki kriter ağılıklarıyla çarpılmıştır. Tablo 4'te gösterildiği gibi toplam ağırlıklar ve bu ağırlıklara göre elde edilen sıralama gösterilmiştir.

Çizelge 4: TOPSIS yöntemine göre sıralama

\begin{tabular}{|c|c|c|c|c|}
\hline & & & & Sıralama \\
\hline Tesis 1 & 0,119 & 0,346 & 0,743 & 3 \\
\hline Tesis 2 & 0,062 & 0,248 & 0,801 & 1 \\
\hline Tesis 3 & 0,103 & 0,321 & 0,757 & 2 \\
\hline
\end{tabular}

Tablo 4'te de görüldüğü gibi, şirketin şu anki koşullarına göre elde edilen tesis yeri seçimi sıralamasına göre en optimal tesis yerinin Tesis 2 olduğu görülmektedir. Ancak yakın gelecekte olabilecek bazı olaylar dikkate alınmadığından, şirket tarafından bu sıralamanın doğruluğu sorgulanmaktadır.

Genel ÇKKV yöntemleriyle elde edilen sonuçlar esnek bir yapıda değildir. Olağan sonucu etkileyebilecek başka bir durum sisteme dâhil olduğunda, sistemin tekrar bütün ağırlıklar gözden geçirilerek en başından çözülmesi gerekmektedir. Bu durumun, kriterleri ve ağılıkları az sayıda olan problemlerde sorunlara yol açmayacağı düşünülebilir. Ancak çok fazla değişkeni olan sistemlerde, yakın gelecekte gerçekleşebilecek olaylar göz önüne alınarak seçim yapılmadığından, her seferinde tekrar ağırlıklar oluşturulup ona göre çözüm yapmak gerekmektedir. Bu da önceden öngörülebilen bir olay sisteme yansıtılmadığı için, zaman kaybına sebep olmaktadır.

Fabrika müdürlerinin yapılan tesis yeri seçimi konusundaki şüpheleri göz önünde bulundurularak, sistemi çözmek için yakın gelecekte olabilecek muhtemel olayları da içeren KÇKKV yöntemi tercih edilmiştir.

Buna göre, fabrikada yakın zamanda gerçekleşebilecek 3 olay söz konusudur. Illk olarak, fabrikaya üretimi farklı şekilde yönlendirecek ve muhtemel bazı intiyaçları karşılayabilecek A makinesinin satın alınması gibi yakın gelecekte gündeme gelecek bir olay vardır. İkinci olarak, yakın gelecekte olası B tedarikçisiyle 
uzun vadeli anlaşma yapılması gibi bir durum söz konusudur. Bu anlaşmanın yapılması durumunda, B tedarikçisinin konumuna, aynı zamanda tedarik ettiği ürün miktarına ve olası bazı değişken faktörlere de bağlı olarak tesis yeri seçimini etkileyebileceği düşünülmektedir. Son olarak sektörde olan gelişmeler dikkate alındığında; savunma sanayi sektöründe kendini kanıtlamış C firmasının, önde gelen firmalardan biriyle iş birliği yaparak sektöre katılacağı düşünülmektedir. Bu koşullar göz önüne alındığında (0,40,0,30, $0,30)$ kriter ağırlıklarının değişmesi beklenmektedir.

Yukarıdaki koşullar göz önüne alınarak hazırlanmış, girdi vektörü $u_{t}=(a, b, c)$ ve çıktı vektörü $v_{t}=(x, y, z)$ olan sistemin girdi vektörünün elemanları aşağıdaki özelliklere göre belirlenecektir.

$$
\begin{aligned}
& \mathrm{a}=\left\{\begin{array}{cc}
0, & \text { A makinesi ile ilgili bir güncelleme yoksa } \\
1, \quad \text { A makinesi satın alınırsa }
\end{array}\right\} \\
& \mathrm{b}=\left\{\begin{array}{cc}
0, & \text { B tedarikçisiyle ilgili bir güncelleme yoksa } \\
1, & \text { B tedarikçisiyle anlaşma imzalanırsa }
\end{array}\right\} \\
& \mathrm{c}=\left\{\begin{array}{cc}
0, & \text { C firmasıyla ilgili bir güncelleme yoksa } \\
1, \quad \text { C firması sektöre katılırsa }
\end{array}\right\}
\end{aligned}
$$

Yukarıdaki olayların gerçekleşme durumuna göre girdi vektörü değişecektir. Bu girdi vektöründen doğacak olan çıktı vektörü $v_{t}=(x, y, z)=($ maliyet, kaynaklara erişilebilirlik, çevresel riskler) kriterlerinin ağırlıkları Tablo 2 'de verilen $(0,40,0,30,0,30)$ ağırlıklarından farklı olacaktır.

Yakın gelecekte olabilecek tüm olaylar analiz edilmiştir. Daha sonra her olaydan sonra gerçekleşebilecek diğer olay; yeni ağırlıklar hesaplanarak, sistemin de gerektirdiği tüm katmanlar birbirini izleyecek şekilde hedefe ulaşılmak istenmiştir. Olası tüm girdilerin ve fabrika müdürlerinin öngörüleri sonucunda elde edilmiş değişen çıktıların gösterildiği Katmanlaşma Kavramı Çizelgesi Tablo 5'te verilmiştir. Ardından Tablo 4'teki veriler düzenlenerek Tablo 6'daki farklı evreler için kriter ağırlıkları oluşturulmuş̧tur.

\section{Çizelge 5: Firma için katmanlaşma kavramı çizelgesi}

\begin{tabular}{|l|c|c|c|}
\hline $\mathbf{s}_{\mathbf{t}}$ & $\mathbf{u}_{\mathbf{t}}$ & $\mathbf{s}_{\mathbf{t + 1}}$ & $\mathbf{v}_{\mathbf{t}}$ \\
\hline \multirow{2}{*}{$w_{1}$} & $(1,0,0)$ & $w_{2}$ & $(0,26,0,25,0,49)$ \\
\cline { 2 - 4 } & $(0,1,0)$ & $w_{3}$ & $(0,43,0,19,0,38)$ \\
\cline { 2 - 4 } & $(0,0,1)$ & $w_{4}$ & $(0,36,0,23,0,28)$ \\
\hline \multirow{2}{*}{$w_{2}$} & $(0,1,0)$ & $w_{5}$ & $(0,25,0,14,0,32)$ \\
\cline { 2 - 4 } & $(0,0,1)$ & $w_{6}$ & $(0,27,0,26,0,32)$ \\
\hline \multirow{2}{*}{$w_{3}$} & $(1,0,0)$ & $w_{5}$ & $(0,25,0,14,0,32)$ \\
\cline { 2 - 4 } & $(0,0,1)$ & $w_{7}$ & $(0,19,0,16,0,45)$ \\
\hline \multirow{2}{*}{$w_{4}$} & $(1,0,0)$ & $w_{6}$ & $(0,27,0,26,0,32)$ \\
\cline { 2 - 4 } & $(0,1,0)$ & $w_{7}$ & $(0,19,0,16,0,45)$ \\
\hline \multirow{2}{*}{$w_{5}$} & $(0,0,1)$ & $w_{8}$ & $(0,23,0,25,0,52)$ \\
\hline \multirow{2}{*}{$w_{6}$} & $(0,1,0)$ & $w_{8}$ & $(0,23,0,25,0,52)$ \\
\hline \multirow{2}{*}{$w_{7}$} & $(1,0,0)$ & $w_{8}$ & $(0,23,0,25,0,52)$ \\
\hline
\end{tabular}

Çizelge 6: Farklı evreler için kriter ağırlıkları

\begin{tabular}{|l|c|c|c|c|c|c|c|c|}
\hline Evre & $\mathbf{w}_{\mathbf{1}}$ & $\mathbf{w}_{\mathbf{2}}$ & $\mathbf{w}_{\mathbf{3}}$ & $\mathbf{w}_{\mathbf{4}}$ & $\mathbf{w}_{\mathbf{5}}$ & $\mathbf{w}_{\mathbf{6}}$ & $\mathbf{w}_{\mathbf{7}}$ & $\mathbf{w}_{\mathbf{8}}$ \\
\hline Maliyet & 0,4 & 0,26 & 0,43 & 0,36 & 0,25 & 0,27 & 0,19 & 0,23 \\
\hline Kaynaklara Erişilebilirlik & 0,3 & 0,25 & 0,19 & 0,23 & 0,14 & 0,26 & 0,16 & 0,25 \\
\hline Çevresel Riskler & 0,3 & 0,49 & 0,38 & 0,28 & 0,32 & 0,32 & 0,45 & 0,52 \\
\hline
\end{tabular}


Farklı evrelerdeki değişen kriter ağırlıkları hesaplandıktan sonra Tablo 7'de belirtilen alternatiflerin kriterlere göre farklı evrelerdeki ağırlıkları hesaplanmıştır. Böylelikle $\mathrm{w}_{1}, \mathrm{w}_{2}, \mathrm{w}_{3}, \mathrm{w}_{4}, \mathrm{w}_{5}, \mathrm{w}_{6}, \mathrm{w}_{7}, \mathrm{w}_{8}$ evrelerindeki Tesis 1, Tesis 2, Tesis 3 alternatifleri maliyet, kaynaklara erişilebilirlik ve çevresel riskler kullanılarak ağırlıklar hesaplanmıştır.

\section{Çizelge 7: Alternatiflerin kriterlere göre farklı evrelerdeki ağırıkları}

\begin{tabular}{|l|c|c|c|c|c|c|c|c|}
\hline & $\mathbf{w}_{\mathbf{1}}$ & $\mathbf{w}_{\mathbf{2}}$ & $\mathbf{w}_{\mathbf{3}}$ & $\mathbf{w}_{\mathbf{4}}$ & $\mathbf{w}_{\mathbf{5}}$ & $\mathbf{w}_{\mathbf{6}}$ & $\mathbf{w}_{\mathbf{7}}$ & $\mathbf{w}_{\mathbf{8}}$ \\
\hline Tesis 1 & 0,20 & 0,23 & 0,22 & 0,18 & 0,16 & 0,18 & 0,20 & 0,24 \\
\hline Tesis 2 & 0,21 & 0,23 & 0,21 & 0,18 & 0,15 & 0,19 & 0,18 & 0,23 \\
\hline Tesis 3 & 0,21 & 0,24 & 0,22 & 0,19 & 0,17 & 0,19 & 0,21 & 0,25 \\
\hline
\end{tabular}

Her evrenin gerçekleşme olasılığı birbirinden farklı olduğundan, fabrika müdürlerinin verilerinden faydalanılarak Tablo 8'de gösterilen olasılıklar elde edilmiştir. Her evre için meydana geliş olasılığı dikkate alındığından, daha objektif bir sonuç elde edilmek istenmiştir.

Çizelge 8: Evrelerin gerçekleşme olasılıkları

\begin{tabular}{|c|c|c|c|c|c|c|c|}
\hline $\mathbf{p}_{11}$ & $\mathbf{p}_{12}$ & $\mathbf{p}_{13}$ & $\mathbf{p}_{14}$ & $\mathbf{p}_{15}$ & $\mathbf{p}_{16}$ & $\mathbf{p}_{17}$ & $\mathbf{p}_{18}$ \\
\hline 0,14 & 0,12 & 0,15 & 0,07 & 0,05 & 0,03 & 0,08 & 0,02 \\
\hline
\end{tabular}

Bu veriler denklem (13)'te verilen formülden faydalanılarak son ağırlıklar elde edilmiş ve bu toplam ağırlıklara uygun olarak Tablo 9'daki sıralama bulunmuştur.

Çizelge 9: Alternatiflerin ağırlıkları

\begin{tabular}{|l|c|c|c|c|c|c|c|c|c|c|}
\hline & $\mathbf{w}_{\mathbf{1}}$ & $\mathbf{w}_{\mathbf{2}}$ & $\mathbf{w}_{\mathbf{3}}$ & $\mathbf{w}_{\mathbf{4}}$ & $\mathbf{w}_{\mathbf{5}}$ & $\mathbf{w}_{\mathbf{6}}$ & $\mathbf{w}_{\mathbf{7}}$ & $\mathbf{w}_{\mathbf{8}}$ & Toplam & Sıralama \\
\hline Tesis 1 & 0,029 & 0,028 & 0,033 & 0,013 & 0,008 & 0,005 & 0,016 & 0,005 & 0,137 & 2 \\
\hline Tesis 2 & 0,029 & 0,027 & 0,031 & 0,013 & 0,008 & 0,006 & 0,015 & 0,005 & 0,133 & 3 \\
\hline Tesis 3 & 0,029 & 0,029 & 0,034 & 0,013 & 0,008 & 0,006 & 0,016 & 0,005 & 0,140 & 1 \\
\hline
\end{tabular}

Alternatiflerin ağılıkları incelendiğinde sırasıyla Tesis 3, Tesis 1 ve Tesis 2 en uygun alternatif olarak seçilmiştir. Bu alternatiflerin ağırlıklarının oluşumunda kriter ağırlıkları, olayların olasılıkları alternatifler bazında incelenmiştir.

\section{SONUÇ}

Bu çalışmada, literatüre yeni kazandırılan Katmanlı Çok Kriterli Karar Verme (KÇKKV) yöntemi incelenmiştir. Bu yeni yöntem, geleneksel Çok Kriterli Karar Verme (ÇKKV) yöntemlerinden olan TOPSIS metodu ile kıyaslanmıştır. Yapılan analiz sonucunda, geleneksel ÇKKV yöntemlerine nazaran KÇKKV yönteminin süreç içerisinde daha iyi sonuçlar doğuracağı gözlemlenmiştir. Bunun için Ankara Sincan Organize Sanayi Bölgesi'nde faaliyet gösteren bir fabrikada tesis yeri seçimi için bir vaka analizi gerçekleştirilmiştir. 3 alternatif tesis yeri, 3 ana kriter belirlenmiş ve problem TOPSIS metoduyla çözülmüştür. Yöntem sonucunda Tesis 2, en iyi tesis yeri seçilmiştir. Geleneksel ÇKKV yöntemlerinin yapısı herhangi bir ek değişikliğe müsaade etmemektedir. Bu nedenle yeni bir makine alımı, sektöre yeni bir firmanın katılması gibi süreç içinde gelişebilecek olaylar için başta oluşturulan Geleneksel ÇKKV yöntemi ile yapılan çözüm, işlevsiz hale gelir. Bu durum da para ve zaman kaybına sebebiyet vermektedir. Karar verme problemlerinde süreç içinde yaşanan bu durumlar işletme ve tedarik zinciri nezaretinde verimlilik kayıpları sonucunu doğurur. Çünkü sürece dâhil olan yeni bir olay, gidişatı büyük ölçüde etkileyip bütün yatırım portföyünü boşa çıkarabilir. Endüstrideki tüm kaynakların verimli kullanılması gerektiğinden, yakın gelecekte olabilecek olayları da olasııı mahiyetinde göz önünde bulunduran KÇKKV yöntemi kullanılmıştır. Fabrika yetkilileri ile yapılan görüşmeler sonucunda yakın gelecekte olabilecek üç olay öngörülmüştür. Bunlardan birincisi fabrikaya yeni bir makine alınması konusudur. İkincisi olası bir tedarikçi ile uzun vadeli bir antlaşma yapılması durumudur. Üçüncüsü ise yeni bir firmanın sektöre katılma durumudur. Bu üç olay, kriterler ve 
alternatifler de göz önüne alınarak KÇKKV yöntemi ile tesis yeri seçimi yapılmıştır. Yöntem sonucunda Tesis 3, en iyi tesis yeri seçilmiştir. Aradaki bu farklıık, yakın gelecekte olabilecek olayların optimal seçimi oldukça etkilediğini göstermektedir.

Literatür araştırması bölümünde de belirtilen çalışmalarda görülebildiği gibi uluslararası alanda yöntem, tesis yeri seçimi problemlerinde kullanılmadığı gibi ulusal alanda da yöntemin kullanıldığı herhangi bir çalışmaya rastlanmamıştır. Yöntem, tesis yeri seçimi problemlerinde kullanılması yönüyle özgün bir çalışmadır. Benzer çalışmalar, tesis yeri seçimi problemlerinde yalnızca Geleneksel ÇKKV yöntemlerinin uygulandığı çalışmaları içermektedir. Literatürde gözlendiği üzere yapılan çalışmalarda yakın gelecekte meydana gelebilecek olaylar KÇKKV yönteminde olduğu gibi katmanlı olarak kümülatif şekilde dikkate alınmamıştır. Geleneksel ÇKKV yöntemleri yakın gelecekte dışarıdan gelecek olayları öngörememekte olup her yeni olayda tekrar çözüm yapmayı gerektirmesi yönleriyle dezavantaj oluşturmaktadır. Bu durum KÇKKV yöntemi ile çözülmeye çalışıımıştır. Yöntem Geleneksel ÇKKV yöntemlerinin yapısını bozmamakla birlikte gelecekte karşılaşılabilecek olayları da öngörerek hareket ettiğinden olasılıklara dayalı birçok yol oluşturmaktadır. Bu yönüyle, KÇKKV yöntemi olası olayları oldukça iyi analiz etmekle birlikte birtakım dezavantajları da ortaya çıkmaktadır. Yöntem, eldeki bulgulara ek olarak gelecekte gerçekleşebilecek olaylar için bir öngörü gerektirir. Tüm olayların gerçekleşme olasılıkları hesaplanır ve bunun üzerinden algoritma yapısı kurularak problem analiz edilir.

Bu araştırmanın kısıtılığı, yakın gelecekte olabilecek olayların probleme uygun şekilde analiz edilip yorumlanamamasıdır. Bu sebeple doğru yapılmayan bir olasılık tahmini, süreci geri döndürülemez bir şekilde etkileyecektir. İlgili KÇKKV yönteminin en büyük özelliği yakın gelecekte olabilecek olayları da göz önünde bulundurması olduğundan, yapılan çalışma işlevsiz hale gelecek ve Geleneksel ÇKKV yöntemlerinden bir farkı kalmayacaktır. Süreçler oldukça değişken olduğundan KÇKKV ile çözülecek problem için oldukça iyi bir proje ekibine intiyaç vardır. Proje, mutlaka risk analizi içermelidir. Çünkü analizin doğru sonuca ulaşması için süreç içindeki olaylar oldukça iyi belirlenmeli ve yatırımlar ona göre yapılmalıdır.

Gelecekte yapılan çalışmalarda olasılık tahmini için makine öğrenmesi regresyon yöntemlerinden XGBoost (eXtreme Gradient Boosting) ya da SVM (Support Vector Machines) gibi algoritmalar kullanılarak yapılan tahminler sonucunda gerçeğe oldukça yakın bir olasılık tahmini elde etmek mümkün olacaktır. Yöntem literatüre son yıllarda kazandırıldığından, bu makalenin birçok farklı sektöre entegre edilebilmesi ve diğer ÇKKV yöntemlerine göre daha başarılı sonuçlar vermesi sebebiyle gelecek çalışmalara ışık tutması beklenmektedir. İnsan günlük hayatta sürekli karar verme süreciyle baş başa kaldığından akademik alanda da problem tipleri oldukça geniştir. Aynı zamanda, yöntemi tedarikçi seçimi, otomobil seçimi, kargo firması seçimi ve personel seçimi gibi birçok problemde kullanmak mümkündür. Özellikle yakın gelecekte meydana gelebilecek olayları dikkate alması sebebiyle problemi, gıda sektörü gibi sirkülasyonun sürekli olduğu sektörlerde kullanmak ya da savunma sanayii gibi süreç içinde yaşanan değişikliklerin çok büyük maddi kayıplara sebep olduğu sektörlere entegre etmenin oldukça verimli sonuçlar doğuracağı düşünülmektedir. 


\section{KAYNAKÇA}

ASADABADI, M. R. (2018), The Stratified Multi-Criteria Decision-Making Method, Knowledge-Based Systems, 162 (June), 115-123.

ASADABADI, M. R., SABERI, M. ve CHANG, E. (2017), Logistic Informatics Modelling Using Concept of Stratification (CST), IEEE International Conference on Fuzzy Systems (FUZZ-IEEE), 1-7.

ASADABADI, M. R., SABERI, M. ve CHANG, E. (2018), Letter: The Concept of Stratification and Future Applications, Applied Soft Computing Journal, 66, 292-296.

ASADABADI, M. R. ve ZWIKAEL, O. (2019), Integrating Risk into Estimations of Project Activities' Time and Cost: A Stratified Approach, European Journal of Operational Research, 291 (2), 482-490.

ASHRAFZADEH, M., RAFIEI, F. M., ISFAHANI, N. M. ve ZARE, Z. (2012), Application of Fuzzy TOPSIS Method for the Selection of Warehouse Location : A Case Study, Interdisciplinary Journal of Contemporary Research in Business, 3 (9), 655-671.

CHEN, C. T. (2000), Extensions of the TOPSIS for Group Decision-Making Under Fuzzy Environment, Fuzzy Sets and Systems, 114 (1), 1-9.

ÇALIK, A., (2018), Otomotiv Tedarik Zincirinde Risk Değerlendirmesi için Bulanık AHP ve TOPSıS ile Bütünleşik Bir Yaklaşım, İşletme Araştırmaları Dergisi, 10 (4), 868-886.

DELUKA-TIBLJAS, A., KARLEUSA, B. ve BENAC, C. (2011), AHP Methodology Application in Garage-Parking Facility Location Selection, Promet-Traffic\&Transportation, 23 (4), 303-313.

DEVECI, M., AKYURT, I. Z. ve YAVUZ, S. (2018), A GIS-Based Interval Type-2 Fuzzy Set for Public Bread Factory Site Selection, Journal of Enterprise Information Management, 31 (6), 820-847.

DUMANOĞLU, S. ve ERGÜL, N. (2010), íMKB'de İşlem Gören Teknoloji Şirketlerinin Mali Performans Ölçümü, Mufad Journal, 48, 101-111.

ERDOĞAN, M. ve KAYA, I. (2016), A Combined Fuzzy Approach to Determine the Best Region for a Nuclear Power Plant in Turkey, Applied Soft Computing Journal, 39, 84-93.

ERTUĞRUL, I. (2011), Fuzzy Group Decision Making for the Selection of Facility Location, Group Decision and Negotiation, 20 (6), 725-740.

ERTUĞRUL, İ. ve KARAKAŞOĞLU, N. (2008), Comparison of Fuzzy AHP and Fuzzy TOPSIS Methods for Facility Location Selection, International Journal of Advanced Manufacturing Technology, 39, 783-795.

FARAHANI, R. Z., STEADIESEIFI, M. ve ASGARI, N. (2010), Multiple Criteria Facility Location Problems: A Survey, Applied Mathematical Modelling, 21, 1689-1709.

FORMANECK, S. (2019), A Study of Sustainable Facility Management from a Green Supply Chain Perspective in the United Arab Emirates, Journal of Turkish Operations Management, 3 (2), 314-323.

HENIG, M. I. ve BUCHANAN, J. T. (1996), Solving MCDM Problems: Process Concepts, Journal of Multi-Criteria Decision Analysis, 5 (1), 3-21.

HWANG, C. L. ve YOON, K. (1981), Methods for Multiple Attribute Decision Making, Multiple Attribute Decision Making, 58-191.

KAHRAMAN, C., RUAN, D. ve DOĞAN, I. (2003), Fuzzy Group Decision-Making for Facility Location Selection, Information Sciences, 157, 135-153.

KOÇAK, M. ve ÇALIK, A. (2020), Banka Seçim Tercihlerinin Bulanık Kümelere Dayalı Yeni Bir Karar Verme Çerçevesi ile Değerlendirilmesi, İstanbul Ticaret Üniversitesi Sosyal Bilimler Dergisi, Prof. Dr. Sabri Orman Özel Sayısı, 73-94.

KORKUT, D. S., DOĞAN, A. M., ve BEKAR, İ. (2010), Kuruluş Yeri Seçimini Etkileyen Faktörlerin Düzce İli Açısından Değerlendirilmesi, Düzce Üniversitesi Orman Fakültesi Ormancılık Dergisi, 6 (1), 32-39.

MACCARTHY, B. L., ve ATTHIRAWONG, W. (2003), Factors Affecting Location Decisions in International Operations-A Delphi Study, International Journal of Operations \& Production Management, 23 (7), 794.

MOKHTARIAN, M. N. (2011), A New Fuzzy Weighted Average (FWA) Method Based on Left and Right Scores: An Application for Determining a Suitable Location for a Gas Oil Station, Computers and Mathematics with Applications, 61 (10), 3136-3145. 
MOKHTARIAN, M. N. ve HADI-VENCHEH, A. (2012), A New Fuzzy TOPSIS Method Based on Left and Right Scores: An Application for Determining an Industrial Zone for Dairy Products Factory, Applied Soft Computing Journal, 12 (8), 2496-2505.

MOKHTARIAN, M. N., SADI-NEZHAD, S. ve MAKUI, A. (2014), A New Flexible and Reliable Interval Valued Fuzzy VIKOR Method Based on Uncertainty Risk Reduction in Decision Making Process: An Application for Determining a Suitable Location for Digging Some Pits for Municipal Wet Waste Landfill, Computers and Industrial Engineering, 78, 213-233.

ÖZDAĞOĞLU, A. (2012), A Multi-Criteria Decision-Making Methodology on the Selection of Facility Location: Fuzzy ANP, International Journal of Advanced Manufacturing Technology, 59 (5-8), 787-803.

PARTOVI, F. Y. (2006), An Analytic Model for Locating Facilities Strategically, The International Journal of Management Science, 34, 41-55.

ROUYENDEGH, B. D. ve SAPUTRO, T. E. (2014), Supplier Selection Using Integrated Fuzzy TOPSIS and MCGP: A Case Study, Procedia-Social and Behavioral Sciences, 116, 3957-3970.

SEKER, S. ve AYDIN, N. (2020), Hydrogen Production Facility Location Selection for Black Sea Using Entropy Based TOPSIS under IVPF Environment, International Journal of Hydrogen Energy, 1-14.

TUZKAYA, G., SEMIH, Ö., TUZKAYA, U. R. ve GÜLSÜN, B. (2008), An Analytic Network Process Approach for Locating Undesirable Facilities: An Example from Istanbul, Turkey, Journal of Environmental Management, 88, 970-983.

ÜRETEN, S. (2006), Üretim/İşlemler Yönetimi: Stratejik Kararlar ve Karar Modelleri, Gazi Kitabevi, Ankara.

YANG, J. ve LEE, H. (1997), An AHP Decision Model for Facility Location Selection, Facilities, 15, $241-254$.

YONG, D. (2006), Plant Location Selection Based on Fuzzy TOPSIS, Original Article, 839-844.

ZADEH, L. A. (2016), Stratification, Target Set Reachability and Incremental Enlargement Principle, Information Sciences, 354, 131-139. 